\title{
Asymmetric Mantle Dynamics in the MELT Region of the East Pacific Rise
}

\author{
D. R. Toomey ${ }^{\mathrm{a}^{*}}$, W. S. D. Wilcock ${ }^{\mathrm{b}}$, J. A. Conder ${ }^{\mathrm{c}}$, D. W. Forsyth ${ }^{\mathrm{c}}$, J. D. Blundy ${ }^{\mathrm{d}}$, \\ E. M. Parmentier ${ }^{\mathrm{c}}$, W. C. Hammond ${ }^{\mathrm{a}}$ \\ a Department of Geological Sciences, University of Oregon, Eugene, OR 97403, USA. \\ ${ }^{\mathrm{b}}$ School of Oceanography, University of Washington, Seattle, WA 98195, USA. \\ ${ }^{c}$ Department of Geological Science, Brown University, Providence, RI 02912, USA. \\ ${ }^{\mathrm{d}}$ CETSEI, Department of Earth Sciences, University of Bristol, Bristol BS8 1RJ, UK. \\ Keywords: East Pacific Rise; mid-ocean ridges; mantle convection; hotspots; asthenosphere; superswells \\ * Corresponding author. Fax: +1-541-346-4692 \\ E-mail: drt@newberry.uoregon.edu
}

\begin{abstract}
The MELT Experiment found a surprising degree of asymmetry in the mantle beneath the fast-spreading, southern East Pacific Rise [1-6]. Pressure-release melting of the upwelling mantle produces magma that migrates to the surface to form a layer of new crust at the spreading center about $6 \mathrm{~km}$ thick [7]. Seismic and electromagnetic measurements demonstrated that the distribution of this melt in the mantle is asymmetric $[2,3,6]$; at depths of several tens of kilometers, melt is more abundant beneath the Pacific plate to the west of the axis than beneath the Nazca plate to the east. MELT investigators attributed the asymmetry in melt and geophysical properties to several possible factors: asymmetric flow passively driven by coupling to the faster moving Pacific plate; interactions between the spreading center and hotspots of the south Pacific; an off-axis center of dynamic upwelling; and/or anomalous melting of an embedded compositional heterogeneity $[1-4,6]$. Here we demonstrate that passive flow driven by asymmetric plate motion alone is not a sufficient explanation of the anomalies.

Asthenospheric flow from hotspots in the Pacific superswell region back to the migrating ridge axis in conjunction with the asymmetric plate motion can create many of the observed anomalies.
\end{abstract}




\section{Introduction}

The southern East Pacific Rise (SEPR) between $0^{\circ}$ and $30^{\circ} \mathrm{S}$ accounts for more than $20 \%$ of the Earth's annual budget of plate creation, an amount exceeding that of the Mid-Atlantic and southwest Indian Ridges combined [8]. It was within this region of pronounced upwelling, near $17^{\circ} \mathrm{S}$, that the Mantle ELectromagnetic and Tomography (MELT) experiment was conducted (Fig. 1). In combination with earlier studies, the MELT experiment revealed asymmetries in structure that extend from the seafloor through at least the upper $100 \mathrm{~km}$ of the mantle. The region west of the rise, relative to the east, is characterized by faster absolute plate motion in the hotspot reference frame [9], slower seafloor subsidence [10], more abundant seamounts [5], less dense mantle $[5,7,11]$, greater shear wave splitting [4], lower seismic velocities [2, 3], and higher electrical conductivity [6]. Higher temperatures and/or greater melt concentrations beneath the Pacific plate can reduce the seismic velocities and density, increase the conductivity and create more off-axis volcanism in the form of seamounts. With nearly symmetric spreading [9], faster motion of the Pacific plate forces the spreading center to migrate rapidly westward and induces asymmetric flow in the underlying viscous asthenosphere. Crystalline fabric generated by shearing flow is anisotropic, so the ridge migration may be directly responsible for the asymmetry in shear wave splitting [4]. To explore whether this and other geophysical anomalies may be attributed to the pattern of mantle flow, we constructed a series of numerical models with varying boundary conditions, mapping out the predicted shape of the melt production region, the subsidence of the seafloor with age and the seismic signature of shear-induced anisotropy.

\section{Model Setup}

The two-dimensional modeling domain (Fig. 2) measures $4000 \mathrm{~km} \times 670 \mathrm{~km}$ and is fixed to the ridge reference frame. Kinematic boundary conditions, which drive mantle flow, are imposed to reproduce the motion of the SEPR in the hotspot reference frame. The side boundaries are open to flow, whereas the bottom and top boundaries are closed. Thus, we 
assume that flow from the lower mantle to the upper mantle does not occur in the vicinity of the ridge, but instead occurs beyond the lateral limits of our modeling domain (this is discussed further below). Along the leftmost side of the modeling domain we introduce either an anomaly in pressure, $\Delta \mathrm{P}$, or an anomaly in potential temperature, $\Delta \mathrm{T}$, that lies at depths below the base of the lithosphere and above a bottom depth for the asthenosphere, $\mathrm{h}_{\mathrm{s}}$ (see figure). Temperature is expressed as potential temperature and the top and bottom boundary conditions are $0^{\circ} \mathrm{C}$ and $\mathrm{T}_{\mathrm{m}}=$ $1257^{\circ} \mathrm{C}$.

We consider the following simplified equations for the conservation of mass, momentum and energy

$$
\begin{aligned}
& \nabla \cdot \mathbf{u}=-\dot{M} \\
& \nabla P=\nabla \cdot(\mu \nabla \mathbf{u}) \\
& \frac{\partial T}{\partial t}+u \cdot \nabla T=\kappa \nabla^{2} T-\frac{L}{c_{p}} \dot{M}
\end{aligned}
$$

where $\mathbf{u}$ is the mantle velocity, $\dot{M}$ is the fractional rate of melt production, $P$ is the dynamic pressure, $\mu$ is the dynamic viscosity, $c_{p}$ is specific heat capacity, $T$ is the temperature, $t$ is the time, $\kappa$ is the thermal diffusivity and $L$ the latent heat of melting. We do not model the transport of the melt phase but the conservation of mass assumes that melt is extracted efficiently. Although near-ridge-axis buoyancy forces may be locally important, they are not believed to contribute significantly to the forces driving plate motions and for this reasons we do not include them in our simplified approach.

Mantle viscosity is a function of pressure and temperature and for numerical simplicity is approximated as a Newtonian fluid:

$$
\mu=\mu_{0} \exp [(E+P(z) V) / R T]
$$

where $E$ is the activation energy, $z$ is the depth, $V$ is the activation volume and $R$ is the ideal gas constant. The pre-exponential term defines a reference viscosity. To allow a linear 
approximation to the non-linear rheology, the activation terms quoted herein $(E$ and $V)$ are reduced by half in the calculations [12].

We seek steady state solutions numerically using two methods. The first is a seconddegree-accurate finite-volume formulation based on the SIMPLER algorithm [13, 14]. The second is a hybrid finite-element finite-difference algorithm $[15,16]$. Solutions are obtained on a $128 \times 64$ grid with a finer horizontal grid spacing near the ridge axis.

\section{Modeling Results}

Figures $3 \mathrm{a}$ and $\mathrm{b}$ show the predicted streamlines for different combinations of the activation energy and volume. The models differ primarily in their activation volumes; the smaller activation volume results in a nearly uniform viscosity within the upper mantle while the larger value leads to a hundred-fold increase. Results for the smaller activation volume (Figure 3a) show that above $250 \mathrm{~km}$ depth streamlines are approximately symmetric with respect to the spreading center and upwelling is near-vertical within one hundred kilometers of the rise. Streamlines for the larger activation volume (Figure $3 b$ ) result in return flow to the ridge that is more confined toward the surface and notably asymmetric within the upper $250 \mathrm{~km}$. At depths less than the maximum depth of melt production (about 150 to $200 \mathrm{~km}$ for hydrous melting) these two solutions represent different styles of upwelling (i.e., return flow to the ridge is either deep and near vertical or it is shallow and asymmetric). An even larger activation volume, as reported by some mineral physics experiments [17], gives rise to a more intense focusing of return flow toward the surface. Allowing influx through the bottom of the region, the $660 \mathrm{~km}$ discontinuity, tends to make the streamlines more vertical. In performing the calculations we have assumed a linear anhydrous mantle solidus. In the presence of a small amount of water, the mantle will melt under water-undersaturated conditions (i.e. low water activity) at temperatures below the anhydrous solidus. This will lead to a deeper onset of melting than that in our calculations [18]. The exact depth at which "damp" melting will begin depends on the water 
content of the nominally anhydrous upper mantle, which is presently poorly constrained. For this reason we have confined our calculations to the anhydrous case.

The modeling may be used to predict the shape of the melt production region, the isostatic subsidence of the seafloor with age and the shear-induced seismic anisotropy. Figs $3 \mathrm{a}$ and $b$ show that the asymmetry in flow induced by westward migration of the SEPR does not give rise to asymmetric melt production. This is because the onset of melting, which is controlled by the depth at which mantle crosses its solidus, is independent of the flow field. The total width of the melt-producing region depends on the viscosity structure and increases as the return flow to the ridge is confined toward the surface (Fig. 3b). To a good approximation, migration of the ridge or asymmetric plate motion simply superimposes a uniform horizontal shear on the flow induced by plate separation, leaving the symmetry of the rates of upwelling unchanged. This prediction is inconsistent with the observations of the MELT experiment, which document a pronounced asymmetry in the distribution of melt within a few hundred kilometers of the rise axis $[1-3,6]$. Thus we conclude that westward migration of the SEPR alone cannot cause the asymmetries documented for this area.

To generate asymmetries in melting and seafloor subsidence that are consistent with the observations, we require either that the asthenosphere to the west of the rise be anomalously hot, relative to both the underlying mesosphere and to the asthenosphere to the east of the rise (Fig. 4) or that there be a dynamic component to the flow (Fig. 6). Thermal anomalies are introduced by imposing a boundary condition on inflow temperature on the westernmost side of the modeling domain, located $2000 \mathrm{~km}$ from the rise (Fig. 2). This distance is arbitrary and it is chosen to be large in order to demonstrate that moderate asthenospheric temperature anomalies can persist over great distances. The introduction of the inflow temperature anomaly reduces the mantle viscosity west of the rise thereby enhancing return flow from the asthenospheric channel to the spreading center. Fig. 4 shows that the combination of an asymmetric mantle flow field with a hot and thin asthenosphere produces an asymmetry in the shape of the dry melt production region, primarily because melting begins at greater depth in a hotter mantle. We varied both the 
thickness $\left(\mathrm{h}_{\mathrm{s}}\right)$ and the temperature anomaly of the inflow boundary condition to determine their effects on the shape of the melt production region. The melting region is notably asymmetric when $h_{s}$ is between 150 to less than $300 \mathrm{~km}$. As $h_{s}$ increases to and beyond $300 \mathrm{~km}$ depth, the melting region becomes approximately symmetric, since the temperature of the material flowing into the upwelling region on both sides of the axis is then nearly uniform.

A hot asthenospheric channel to the west of the rise can produce seafloor subsidence comparable to that observed. For boundary conditions of $h_{s}=170 \mathrm{~km}$ and an inflow temperature anomaly of $100^{\circ} \mathrm{C}$, Figure 5a shows the isostatically predicted seafloor depth within $1000 \mathrm{~km}$ of the rise. As expected, the predicted degree of asymmetric subsidence depends on both the inflow temperature anomaly and the thickness of the asthenosphere. Putting firm bounds on the values of these parameters may be possible with a more detailed analysis. We note that larger potential temperature anomalies (e.g. $200^{\circ} \mathrm{C}$ ) over-predict the amount of asymmetric subsidence and also result in a more symmetric shape for the melt production region. Thus there is a tendency in solutions explored thus far to favor a thin asthenosphere characterized by a temperature anomaly that is moderate relative to that predicted for mantle plumes [19].

Deformation induced by mantle flow gives rise to crystallographic alignment of minerals and thus detectable anisotropy in seismic wave speeds [20]. While the development of lattice preferred orientation is a topic of vigorous research [21-25], we can obtain an approximate estimate of the anisotropic structure by calculating the finite strain [26, 27]. In agreement with previous studies, we assume that strains greater than $200 \%$ result in near complete alignment of crystallographic axes and that the crystallographic a-axes of olivine are aligned in the direction of maximum elongation [21]. This allows us to assess the effects of flow-induced anisotropy on the cross-axis variation in the delay time of vertically traveling body waves. Fig. 5b shows a comparison of the observed delay times between polarized shear waves with those predicted for different models of return flow. The integration of the strain history was [26] was calculated for parcels of mantle at depths less than $300 \mathrm{~km}$. A predicted delay time between polarized shear waves was calculated along a vertical ray path using an elastic stiffness tensor for an olivine-rich 
peridotite [28]. Flow models described by return flow that is deep and near vertical (Fig. 3a) do not yield pronounced east-west variations in the predicted delay times. Confining the return flow toward the surface (Fig. 3b), increases the near-axis asymmetry in the delays of polarized shear waves, but the predicted results do not match the observations well. The predictions are most consistent with the observations when shallow asymmetric return flow acts in conjunction with an asthenospheric temperature anomaly (Fig. 4). On the basis of our modeling, we conclude that many of the structural anomalies observed in the MELT area can be explained by the interaction of an asymmetric mantle flow field, driven by the westward migration of the SEPR, with an asthenospheric channel that is thin and hot.

One possible origin of hot asthenosphere is the South Pacific Superswell [29, 30], a region to the west of the East Pacific Rise that is characterized by anomalously large volumes of hotspot volcanism, enriched mantle, and elevated seafloor. Recent global tomography studies $[31,32]$ reveal that shear wave velocities are anomalously low at asthenospheric depths in a region extending from the SEPR toward the South Pacific Superswell (Fig. 1). Phipps Morgan et al. [33] proposed that upwelling of deeper mantle in the vicinity of the superswell supplies the asthenosphere with material that is relatively hot and geochemically enriched and that there may be a dynamic component to asthenospheric flow; a pressure gradient generated by density anomalies in the superswell area that helps drive flow back toward the East Pacific Rise [16].

We have explored the effects of a possible horizontal pressure gradient on flow, upwelling, and melting near the SEPR in order to introduce a dynamic component to the melting. We impose a pressure differential on the left (Pacific) side of the model regime in the numerical models (Fig. 2), with or without an imposed thermal anomaly. We find that a marked asymmetry in melting can be created by excess pressure alone (Fig. 6). The model pressure gradient tends to drive flow in the low viscosity asthenospheric channel from west to east across the ridge axis. Moving from west to east, the lithosphere thins approaching the SEPR, expanding the depth range of the low viscosity channel. Some of the pressure-driven flow moves upward beneath the thinning lithosphere, enhancing melt production beneath the Pacific 
plate. To the east of the axis, the pressure-driven flow is forced downwards by the thickening of the Nazca plate, reducing the upwelling velocity and melt production. Our models show that if the pressure-driven flow is rapid enough, it can abruptly shut off melting to the east of the axis (Fig. 6). An abrupt shutoff is consistent with the rapid decrease in conductivity to the east of the axis [6] and sharp drops in the delay of S waves [3]. Depending on the viscosity of the asthenosphere, these pressure gradients could create a significant topographic gradient in addition to the thermal subsidence [33]. In the MELT area, the topography can be accurately represented as the sum of a symmetric subsidence proportional to the square root of age of the seafloor plus a linear gradient [34] that could be created by a pressure gradient (Figure 5a). Horizontal pressure gradients can produce stronger asymmetry in melt production than thermal anomalies alone, but to produce such asymmetry, strong, across-axis flow is required, which leads to no predicted asymmetry in shear wave splitting.

\section{Discussion}

We have shown that asymmetric melt production and seafloor subsidence can be created by asthenospheric flow in a system with plates migrating at different rates. Along the SEPR, subsidence is asymmetric from about $6^{\circ} \mathrm{S}$ to $23^{\circ} \mathrm{S}$ [34], roughly the same latitude range as the South Pacific Superswell. The results presented here support the hypothesis that hotspots feed the oceanic asthenosphere which subsequently provides the return flow to the ridge axis [33]. The flow probably involves anomalously hot mantle that actively flows away from the hotspot, but either anomalous temperatures or pressure-driven flow are sufficient to cause asymmetries in melt production that may be responsible for the asymmetries in seismic velocities, seamount abundance, seafloor subsidence, and electrical conductivity. No off-axis center of dynamic upwelling is required to create asymmetry, but convective overturn with downwelling to the east of the axis could play the same role as a strong, horizontal pressure gradient in abruptly terminating melt production beneath the Nazca plate. Such a pattern of small-scale convection could be superimposed on or triggered by advection of thermal anomalies from the superswell. 


\section{Acknowledgements}

We would like to thank Alessandro Forte and Greg Houseman for their suggestions. JDB would like to thank the Fulbright Commission for a Research Scholarship at the University of

Oregon in 1999. This work was supported by the National Science Foundation grants OCE9814330, OCE-0002501, OCE-0002628 and OCE-9812208. 


\section{Figure Captions}

Fig. 1. Predicted seafloor bathymetry [35] in the vicinity of the Southern East Pacific Rise (SEPR) and the South Pacific Superswell. Bathymetry is shaded, illumination angle is from the northwest. The inner box shows the location of the MELT Experiment which was centered on the SEPR at $17^{\circ} \mathrm{S}$. In the vicinity of the MELT region absolute plate motions in the hotspot reference frame and relative plate motions in the ridge reference frame are approximately parallel to one another [9]. Vectors near the inner box show the absolute and relative plate velocities (black and open arrows, respectively), and the motion of the rise axis in the hotspot reference frame (gray arrow). The red bar parallel to the SEPR shows the approximate extent of the rise axis which displays asymmetric axial topography [34]. The South Pacific Superswell $[29,30]$ is located in the region of French Polynesia. Superimposed on the bathymetry are contours of variations in the isotropic shear wave velocity at $150 \mathrm{~km}$ depth from a recent global tomography study [32]. Contours are labeled in percent deviation from a radially symmetric reference model. Velocities are lowest beneath the SEPR and asymmetric relative to the rise axis, with lower velocities extending further to the west and into the vicinity of the superswell (see also Fig. 3 of Ekstrom and Dziewonski [32])

Fig. 2. Configuration of the two-dimensional, rise-perpendicular modeling domain. The model is ridge-centered, $4000 \mathrm{~km}$ in lateral extent and $670 \mathrm{~km}$ deep. Relative plate motions are imposed as a top boundary condition, whereas the motion of the ridge in the hotspot reference frame is imposed as a bottom boundary condition. Along the leftmost side of the modeling domain we introduce either an anomaly in pressure, $\Delta \mathrm{P}$, or an anomaly in potential temperature, $\Delta \mathrm{T}$, that lies at depths below the base of the lithosphere and above a bottom depth for the asthenosphere, $\mathrm{h}_{\mathrm{s}}$. Results without an inflow anomaly in either temperature or pressure are shown in Fig. 3. Results with an inflow temperature or pressure anomaly are shown in Fig. 4 and Fig. 6, respectively. 
Fig. 3. a: Streamlines and the shape of the anhydrous melt production region for no inflow temperature anomaly, an activation energy, $E$, of $540 \mathrm{kJmol}^{-1}$ and an activation volume, $V$, of 3.4 $\mathrm{x} 10^{-6} \mathrm{~m}^{3} \mathrm{~mol}^{-1}$. These values of $E$ and $V$ yield a nearly uniform viscosity in the upper mantle [36]. Gray shades change at intervals of $0.2,0.4,0.6$ and 0.8 of the maximum melt production rate; the melt present region ( 0.02 of the maximum melt production rate) is demarcated by the dashed line. Within $100 \mathrm{~km}$ of the rise axis and at depths less than about $250 \mathrm{~km}$ the streamlines are sub-vertical. The shape of the melting region is symmetric about the rise and the melt present region has a half-width of about $200 \mathrm{~km}$. b: Results for $\mathrm{E}=540 \mathrm{kJmol}^{-1}, \mathrm{~V}=20.0 \times 10^{-}$ ${ }^{6} \mathrm{~m}^{3} \mathrm{~mol}^{-1}$, and $\mathrm{E}=600 \mathrm{kJmol}^{-1}, \mathrm{~V}=12.0 \times 10^{-6} \mathrm{~m}^{3} \mathrm{~mol}^{-1}$ above and below $200 \mathrm{~km} \mathrm{depth}$, respectively; equivalent to a 100 fold increase in viscosity in the uppermost mantle. Shading and contouring of melt production and melt present regions are identical to a. In this case the streamlines are notably asymmetric about the rise. Asymmetric mantle streamlines alone do not give rise to asymmetric melting, however, the greater viscosity gradient with depth, relative to a, increases the half-width of the melt present region to about $300 \mathrm{~km}$.

Fig. 4. Streamlines and shape of the dry region of melt production for activation energies and volumes identical to Fig. $3 \mathrm{~b}$ and an inflow temperature anomaly of $100^{\circ} \mathrm{C}$ with $\mathrm{h}_{\mathrm{s}}=170 \mathrm{~km}$. The inflow temperature anomaly results in a more focused return flow within the asthenosphere and pronounced asymmetries in the shape of the melting region. Gray shades change at intervals of $0.2,0.4,0.6$ and 0.8 of the maximum melt production rate; the melt present region $(0.02$ of the maximum melt production rate) is demarcated by the dashed line.

Fig. 5. a: The observed and isostatically predicted subsidence of the seafloor with distance from the rise axis. Isostatic depth anomalies are based on mantle density anomalies calculated assuming a coefficient of thermal expansion of $3 \times 10^{-5} \mathrm{~K}^{-1}$ and a mantle density of $3300 \mathrm{~kg} / \mathrm{m}^{3}$. For the model of Fig. 6, the dynamic effect of the imposed pressure gradient is added to the isostatic calculation. To the west of the rise the actual seafloor subsides more slowly than to the 
east of the rise (solid line). Models without an asthenospheric temperature or pressure anomaly result in a more symmetric subsidence (dotted line). The subsidence predicted from the model in Fig. 4 (dashed line) and Fig. 6 (dashed-dotted line) compare well with the observations. b: Cross-axis variation in the observed delay time between polarized shear waves [4] compared with those predicted for the flow models. Observations (open circles) are shown with their one standard deviation uncertainties. Predictions for flow models of Figs. 3a and b and Fig. 4 are shown as dotted, lightly dashed, and dashed lines, respectively; shear wave splitting for the model shown in Fig. 6 is predicted to be constant (not shown). Flow driven by ridge migration alone (Fig. 3) does not predict an asymmetry in delay times that is comparable to the observations. Models with an asthenospheric temperature anomaly and asymmetric flow at depths less than $300 \mathrm{~km}$ (Fig. 4) predict greater amounts of shear wave splitting to the west of the rise, in agreement with the observations.

Fig. 6. Streamlines and melt production region beneath a spreading center with pressure driven asthenospheric flow. Across-axis pressure driven flow extends the upwelling region on the upwind side and reduces the extent of upwelling on the downwind side as flow is forced downward beneath the thickening lithosphere. The applied pressure gradients increase the velocity within the asthenosphere to magnitudes larger than the spreading rate. Asthenospheric velocities in this model reach rates upwards of $300 \mathrm{~mm} / \mathrm{yr}$. The given model has an activation volume of $16 \times 10^{-6} \mathrm{~m}^{3} \mathrm{~mol}^{-1}$, activation energy of $500 \mathrm{kJmol}^{-1}$ and a pressure gradient of 2000 $\mathrm{Pa} / \mathrm{km}$ (assuming a normalization viscosity of $10^{21} \mathrm{~Pa}-\mathrm{s}$ at $600 \mathrm{~km}$ depth). Greater or lesser assumed normalization values for the viscosity structure require a correspondingly greater or lesser applied pressure gradient to achieve the same result. 


\section{References}

[1] MELT Seismic Team, Imaging the deep seismic structure beneath a mid-ocean ridge: The MELT experiment, Science 280 (1998) 1215-1218.

[2] D.W. Forsyth, S.C. Webb, L.M. Dorman and Y. Shen, Phase velocities of Rayleigh waves in the MELT experiment on the East Pacific Rise, Science 280 (1998) 1235-1238.

[3] D.R. Toomey, W.S.D. Wilcock, S.C. Solomon, W.C. Hammond and J.A. Orcutt, Mantle seismic structure beneath the MELT region of the East Pacific Rise from P and S wave tomography, Science 280 (1998) 1224-1227.

[4] C.J. Wolfe and S.C. Solomon, Shear-wave splitting and implications for mantle flow beneath the MELT region of the East Pacific Rise, Science 280 (1998) 1230-1232.

[5] D.S. Scheirer, D.W. Forsyth, M.H. Cormier and K.C. Macdonald, Shipboard geophysical indications of asymmetry and melt production beneath the East Pacific Rise near the MELT experiment, Science 280 (1998) 1221-1224.

[6] R.L. Evans, P. Tarits, A.D. Chave, A. White, G. Heinson, J.H. Filloux, H. Toh, N. Seama, H. Utada, J.R. Booker and M.J. Unsworth, Asymmetric electrical structure in the mantle beneath the East Pacific Rise at $17^{\circ} \mathrm{S}$, Science 286 (1999) 752-756.

[7] J.P. Canales, R.S. Detrick, S. Bazin, A.J. Harding and J.A. Orcutt, Off-axis crustal thickness across and along the East Pacific Rise within the MELT area, Science 280 (1998) 1218-1221.

[8] B. Parsons, The rates of plate creation and consumption, Geophys. J. R. Astr. Soc. 67 (1981) 437-448.

[9] A.E. Gripp and R.G. Gordon, Current plate velocities relative to the hotspots incorporating the Nuvel-1 global plate motion model, Geophys. Res. Lett. 17 (1990) $1109-1112$.

[10] J.R. Cochran, Variations in subsidence rates along intermediate and fast spreading midocean ridges, Geophys. J. R. Astr. Soc. 87 (1986) 421-454.

[11] M.H. Cormier, K.C. Macdonald and D.S. Wilson, A three-dimensional gravity analysis of the East Pacific Rise from $18^{\circ}$ to $21^{\circ} 30^{\prime}$ S, J. Geophys. Res. 100 (1995) 8063 - 8082.

[12] U. Christensen, Convection with pressure- and temperature-dependent non-Newtonian rheology, Geophys. J. R. Astr. Soc. 77 (1984) 343-384.

[13] S.V. Patankar, Numerical Heat Transfer and Fluid Flow, 208 pp., McGraw-Hill, 1980.

[14] S.V. Patankar, A calculation procedure for two-dimensional elliptic situations, Numer. Heat. Trans. 4 (1981) 409-425.

[15] M.G. Braun, G. Hirth and E.M. Parmentier, The effects of deep damp melting on mantle flow and melt generation beneath mid-ocean ridges, Earth Plan. Sci. Lett. 176 (2000) 339-356.

[16] J.A. Conder, D.W. Forsyth and E.M. Parmentier, Asthenospheric flow and the asymmetry of the East Pacific Rise, MELT area, J. Geophys. Res. (in press).

[17] S. Karato and P. Wu, Rheology of the upper mantle: A synthesis, Science 260 (1993) $771-778$.

[18] G. Hirth and D.L. Kohlstedt, Water in the oceanic upper mantle: Implications for rheoology, melt extraction and evolution of the lithosphere, Earth Plan. Sci. Lett. 144 (1996) 93-108.

[19] N.H. Sleep, Hotspot volcanism and mantle plumes, Ann. Rev. Earth Planet. Sci. 20 (1992) 19-43.

[20] A. Nicolas and N.I. Christensen, Formation of anisotropy in upper mantle peridotites - a review, in: K. Fuchs and C. Froidevaux (Eds.), Composition, Structure, and Dynamics of the Lithosphere-Asthenosphere System, American Geophys. Union, Washington D.C.,1987, pp. 111-123.

[21] N.M. Ribe, On the relation between seismic anisotropy and finite strain, J. Geophys. Res. 97 (1992) 8737-8747. 
[22] Y.B. Chastel, P.R. Dawson, H.R. Wenk and K. Bennett, Anisotropic convection with implications for the upper mantle, J. Geophys. Res. 98 (1993) 17757-17771.

[23] S. Zhang and S. Karato, Lattice preferred orientation of olivine aggregates deformed in simple shear, Nature 375 (1995) 774-780.

[24] D.K. Blackman, J.M. Kendell, P.R. Dawson, H.R. Wenk, D. Boyce and J. PhippsMorgan, Teleseismic imaging of subaxial flow at mid-ocean ridges: travel-time effects of anisotripic mineral texture in the mantle, Geophys. J. Intl. 127 (1996) 415-426.

[25] A. Tommasi, Forward modeling of the development of seismic anisotropy in the upper mantle, Earth Plan. Sci. Lett. 160 (1998) 1-13.

[26] D. McKenzie, Finite deformation during fluid flow, Geophys. J. R. Astr. Soc. 58 (1979) 689-715.

[27] C.E. Hall, K.M. Fischer and E.M. Parmentier, The influence of plate motions on three dimensional barck-arc mantle flow and shear wave splitting, J. Geophys. Res. 105 (2000) 28009-28034.

[28] H. Kern, P and S wave anisotropy and shear wave splitting at pressure and temperature in possible mantle rocks and their relation to the rock fabric, Phys. Earth Planet. Int. 78 (1993) 245-256.

[29] M.K. McNutt and A.V. Judge, The superswell and mantle dynamics beneath the South Pacific, Science 248 (1990) 969-975.

[30] M.K. McNutt, Superswells, Rev. Geophys. 36 (1998) 211-244.

[31] W.-J. Su, R.L. Woodward and A.M. Dziewonski, Degree-12 model of shear velocity heterogeneity in the mantle, J. Geophys. Res. 99 (1994) 4945-4980.

[32] G. Ekstrom and A.M. Dziewonski, The unique anisotropy of the Pacific upper mantle, Nature 394 (1998) 168-172.

[33] J. Phipps Morgan, W.J. Morgan, Y.-S. Zhang and W.H.F. Smith, Observational hints for a plume-fed, sub-oceanic asthenosphere and its role in mantle convection, J. Geophys. Res. 100 (1995) 12753-12767.

[34] M.A. Eberle and D.W. Forsyth, Evidence from the asymmetry of fast-spreading ridges that the axial topographic high is due to extensional stresses, Nature 394 (1998) 360-363.

[35] W.H.H. Smith and D. Sandwell, Global seafloor topography from ssatellite altimetry and ship depth soundings, Science 277 (1997) 1956-1962.

[36] F. Béjina, O. Jaoul and R.C. Liebermann, Activation volume of Si diffusion in San Carlos olivine: Implications for upper mantle rheology, J. Geophys. Res. 104 (1999) 25529-25542. 


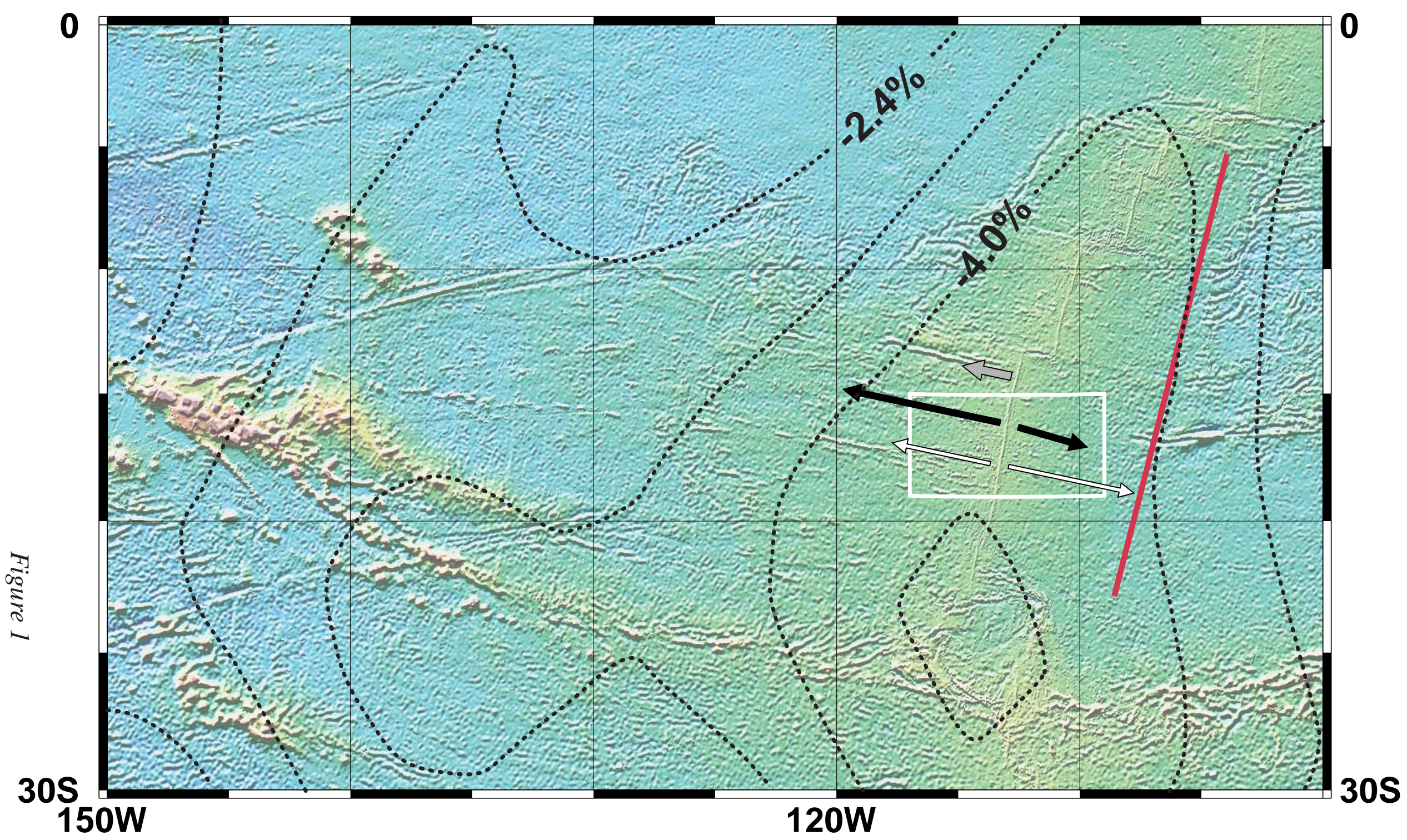




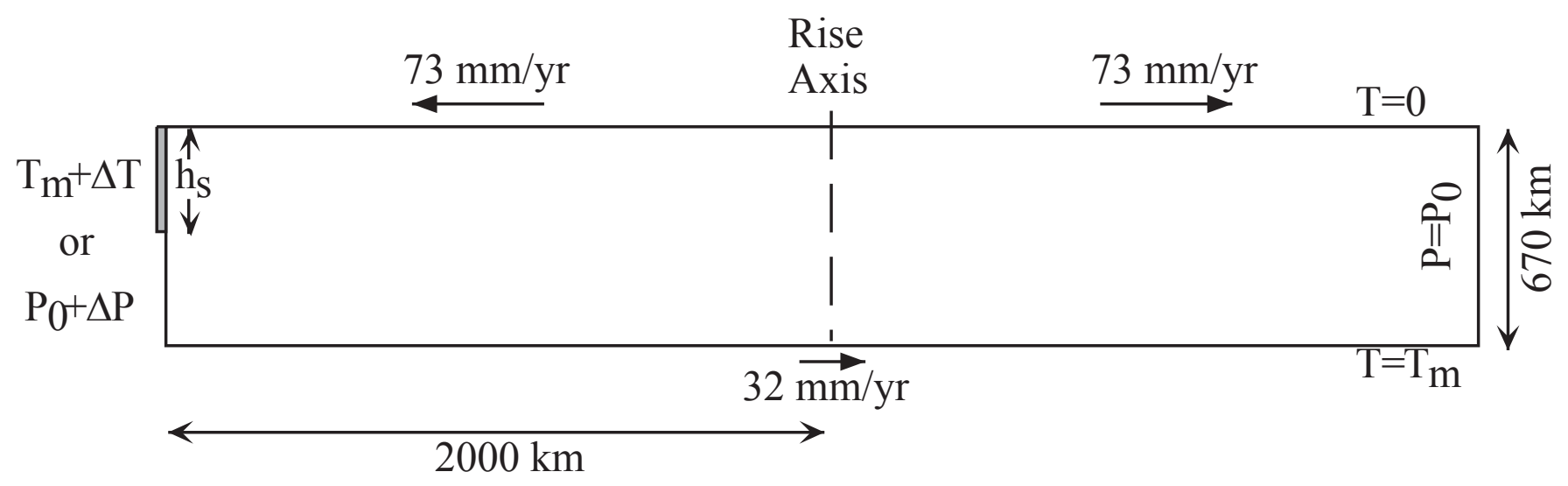

Figure 2 
(a)

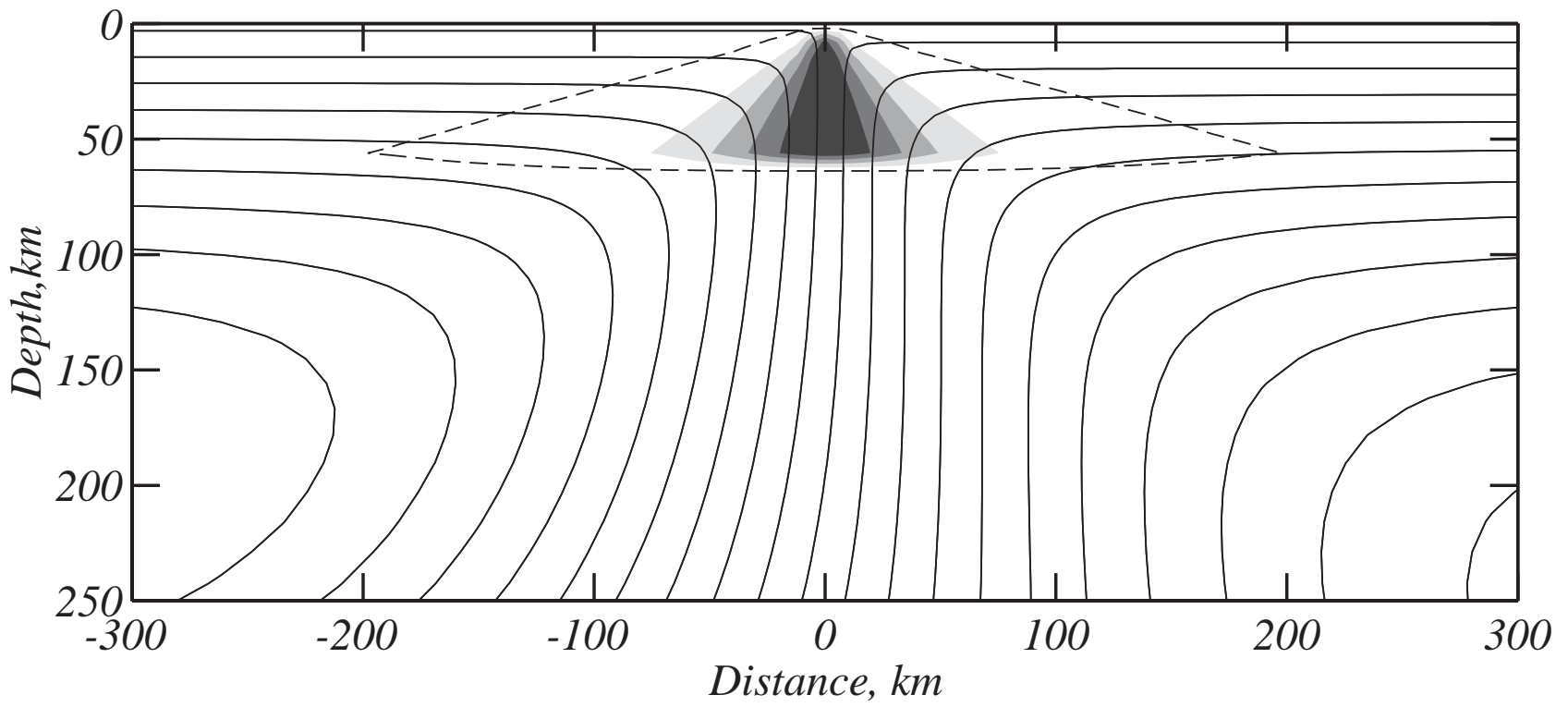

(b)

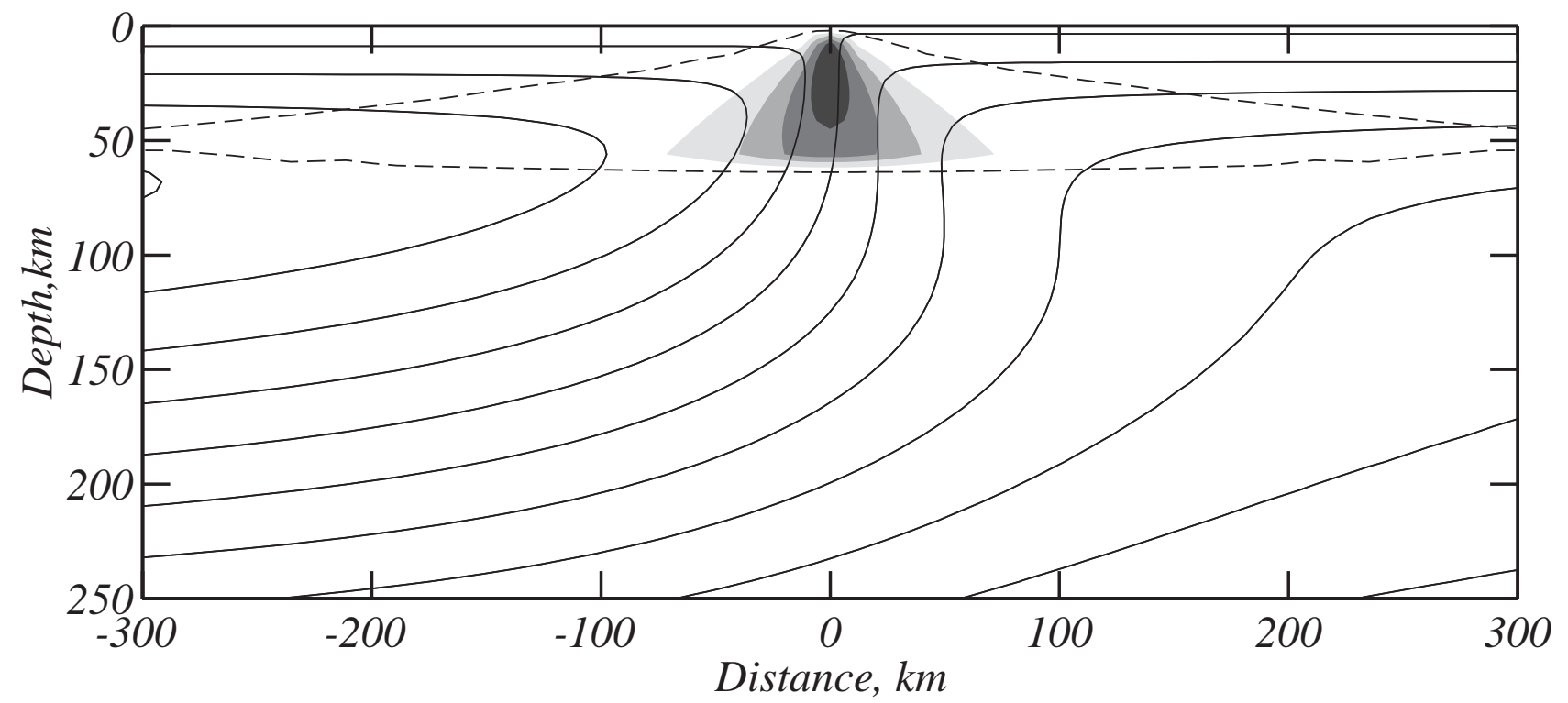

Figure $3 a b$ 


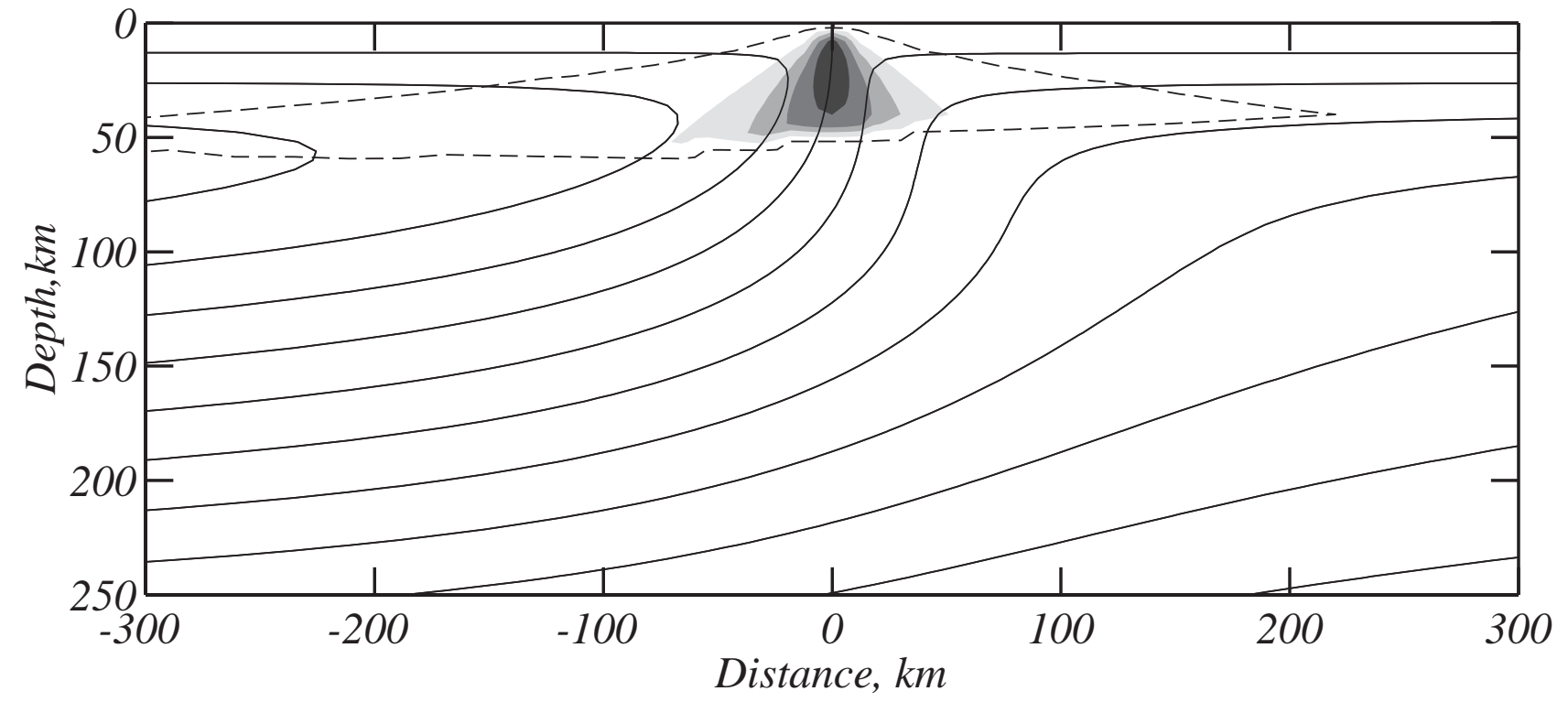

Figure 4 
(a)

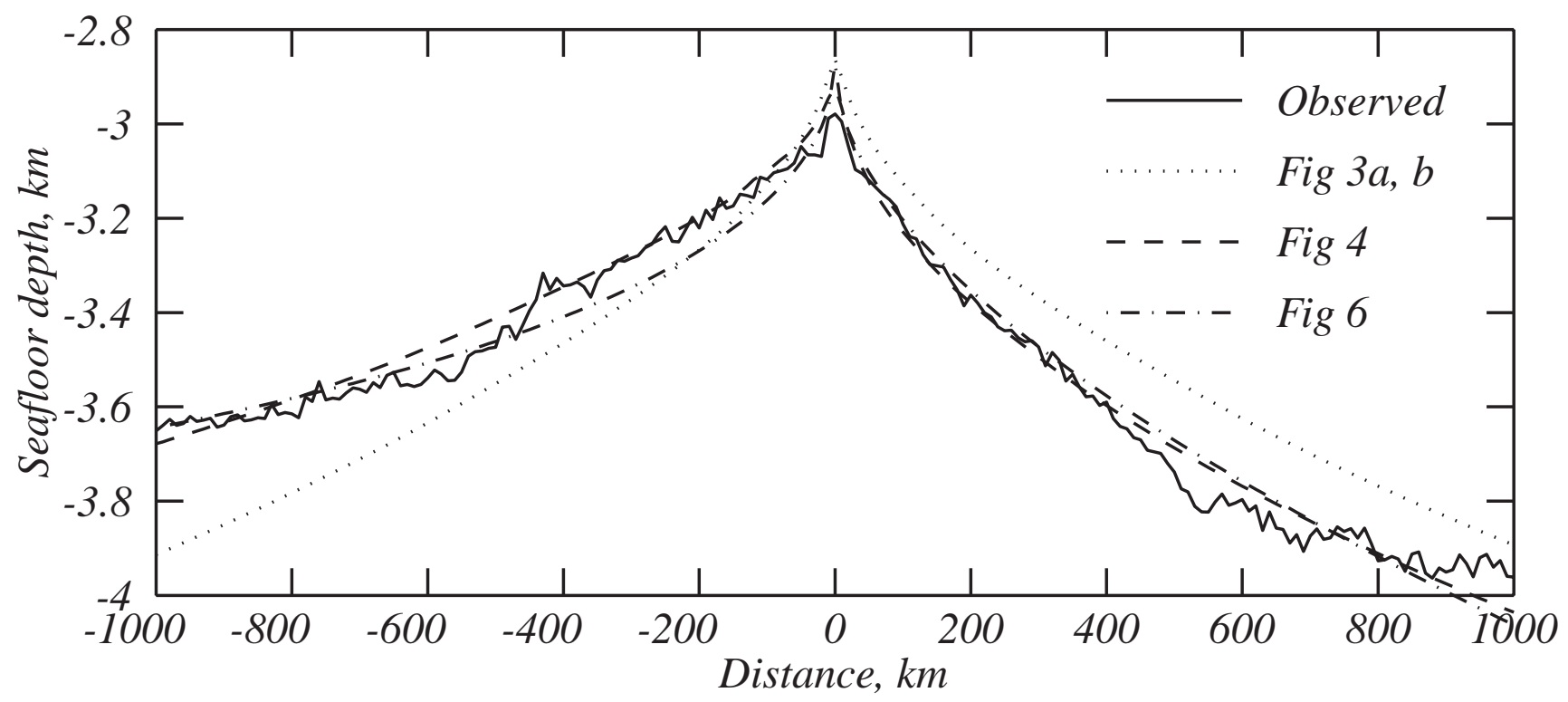

(b)

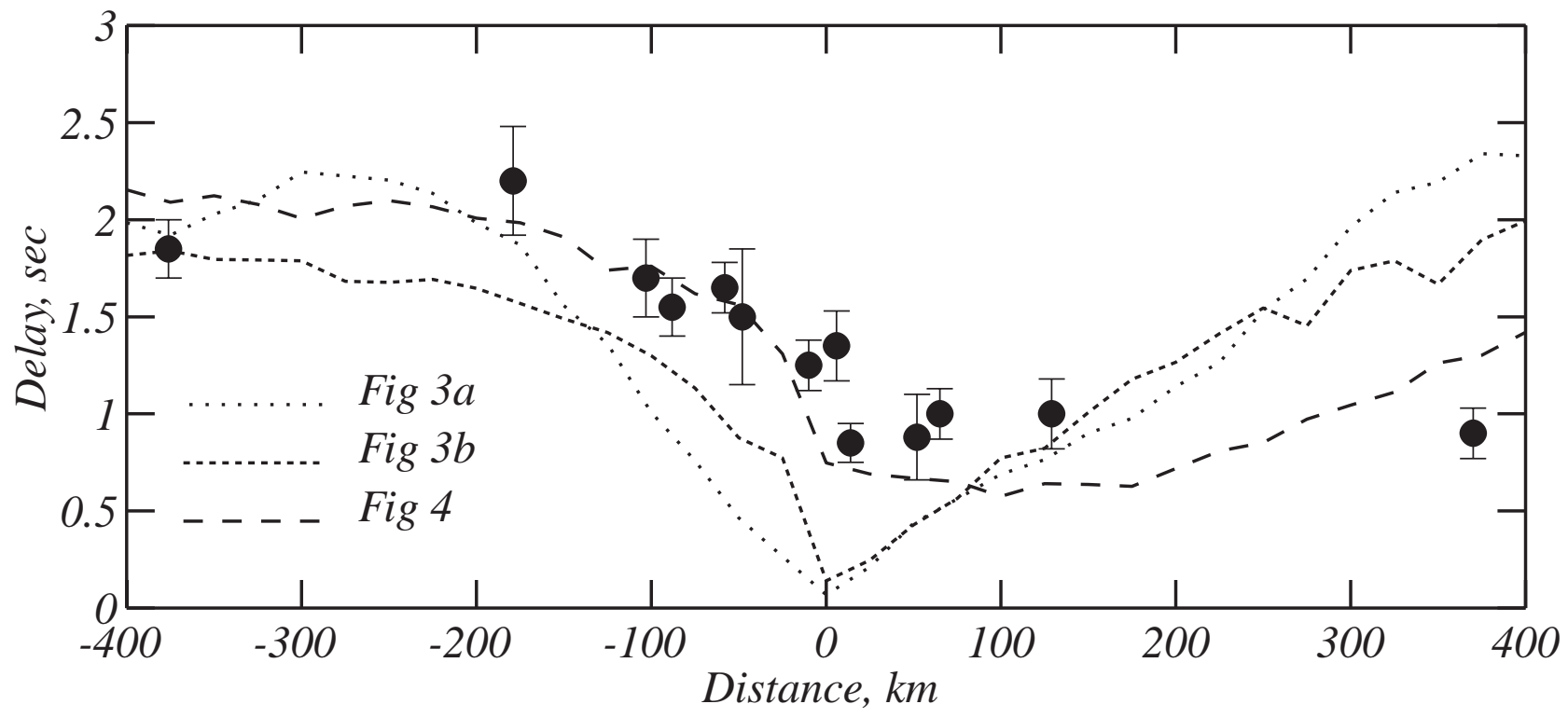

Figure $5 a b$ 


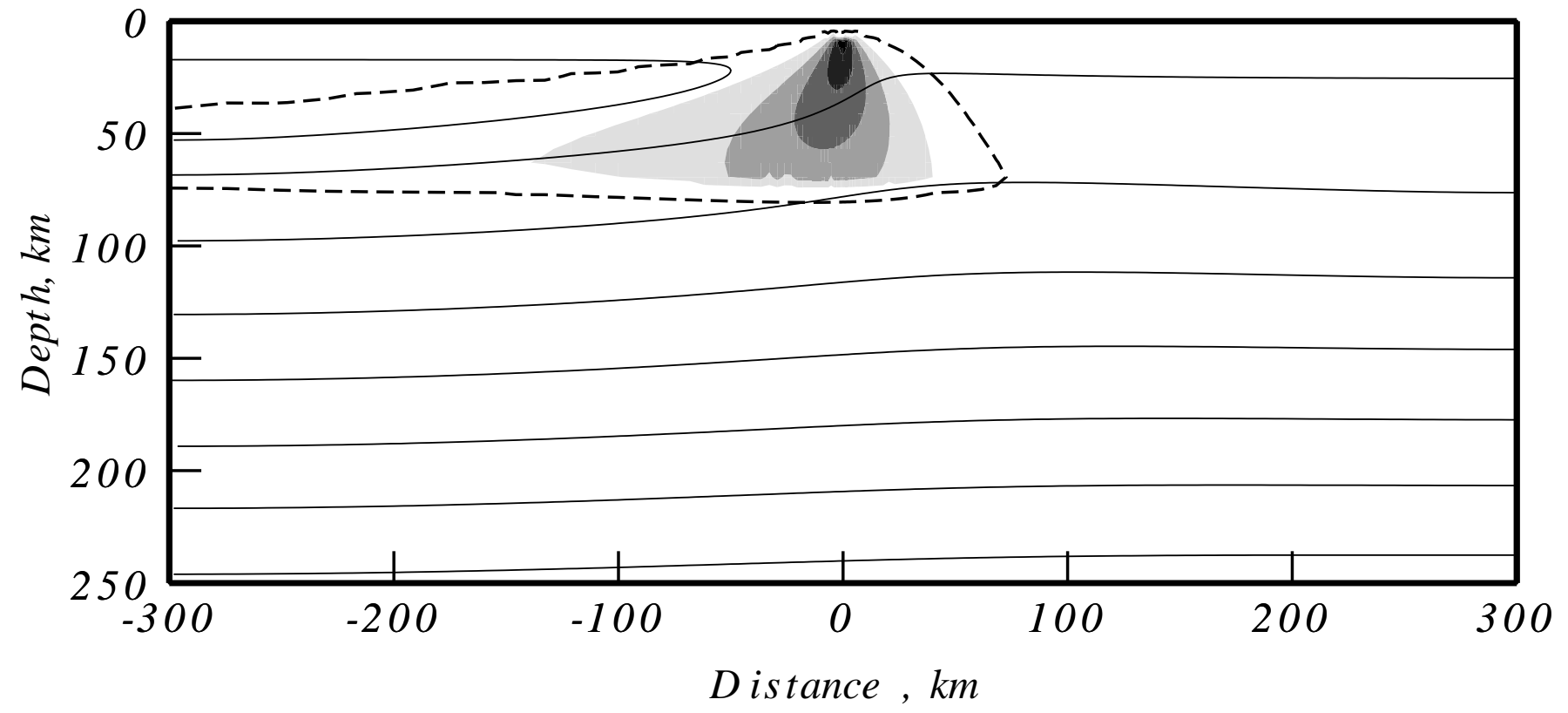

Figure 6 